\title{
Spraying of Composite Liquid Fuels Based on Types of Coal Preparation Waste: Current Problems and Achievements: Review
}

\author{
Roman Volkov (), Timur Valiullin and Olga Vysokomornaya * \\ Research School of High-Energy Physics, National Research Tomsk Polytechnic University, 634050 Tomsk, Russia; \\ romanvolkov@tpu.ru (R.V.); valiullin@tpu.ru (T.V.) \\ * Correspondence: vysokomornaja@tpu.ru
}

check for updates

Citation: Volkov, R.; Valiullin, T.; Vysokomornaya, O. Spraying of Composite Liquid Fuels Based on Types of Coal Preparation Waste: Current Problems and Achievements: Review. Energies 2021, 14, 7282. https://doi.org/10.3390/en14217282

Academic Editor: Byong-Hun Jeon

Received: 23 September 2021

Accepted: 1 November 2021

Published: 3 November 2021

Publisher's Note: MDPI stays neutral with regard to jurisdictional claims in published maps and institutional affiliations.

Copyright: (c) 2021 by the authors. Licensee MDPI, Basel, Switzerland. This article is an open access article distributed under the terms and conditions of the Creative Commons Attribution (CC BY) license (https:// creativecommons.org/licenses/by/ $4.0 /)$.

\begin{abstract}
This article discusses the atomization of composite liquid fuels. A large group of injectors is considered. A comparative analysis of the atomization characteristics (droplet sizes and velocities, jet opening angles) and the influence of the fuel characteristics (density, viscosity, component composition) and the process parameters (the ratio of the fuel-air mass flow rates, the features of the jet formation) has been carried out. Finally, the most effective types of injectors, which provide for the necessary characteristics of fuel atomization for its combustion, have been determined. The most favorable conditions for the applicability of each type of atomization have been formulated. Possible mechanisms of secondary fragmentation of droplets of composite fuels have been analyzed: those resulting from mutual collisions of droplets in the flux and from the interaction with a solid surface as well as those resulting from thermal overheating in the presence of a phase boundary or a large gradient of component volatility. A conclusion is made about the need of using a synergistic effect of primary and secondary atomization of fuel suspension droplets.
\end{abstract}

Keywords: composite liquid fuels; spaying; atomization; nozzle devices; injectors; primary and secondary atomization; collision modes; micro-explosion

\section{Introduction \\ 1.1. Relevance of Composite Liquid Fuels}

The use of fuel compositions as an alternative to conventional combustible liquids is receiving more demand for a number of reasons. One of the main reasons is the rapid depletion of global reserves of oil, gas, and coal along with inexorably increasing power consumption [1]. Unprecedented planet pollution by the wastes of coal and oil production as well as industrial plants and various carbon-containing biological wastes poses great danger [2,3]. Given global energy consumption and the situation with the economy, the use of the above wastes as fuel composition components appears to be a rather rational solution. Countries with rapidly growing economies face serious problems related to high cost of conventional energy resources. The use of natural gas as an energy source is considered the most environmentally friendly option. However, it incurs high costs, and its transportation requires pipelines or ad hoc liquefaction plants. The most demanded power plant fuel is coal due to its relatively low price and simple transportation. However, it has detrimental effect on the environment $[4,5]$. The negative impact of coal production industry is aggravated by the accumulation of menacing amounts of wastes, specifically, sludge, filter cakes, and intermediate stocks. The scale of the problem is exacerbated by the fact that the share of coal power plants in world's leading economies (China, India, USA) exceeds $50 \%$ of total power production, and this share will yet increase in the future.

The main positive aspects of using composite liquid fuels include [6]:

- $\quad$ lower cost as compared with fuel oil or coal in its pure form;

- minimal emissions of harmful substances into the air due to complete combustion of fuel; 
- a possibility to recover a large group of combustible waste as fuel components;

- $\quad$ reduced fire and explosion hazard at power plants due to the presence of water in the composite fuel composition.

In this regard, the research and development of the applicability of fuel compositions based on industrial wastes [7-10] and the technologies of direct coal liquefaction [11,12] have become very active in recent decades. Still, aside from the positive effect, limitations and disadvantages of composite liquid fuels (CLFs) should be borne in mind. Lower combustion heat as compared to coal should be taken into account. The combustion temperature of fuel suspensions based on wastes is also lower. Thus, these factors stipulate high specific rate of fuel consumption required to produce the same amount of energy [6]. Fuel feed lines of CLFs are more prone to corrosion and erosion, since chemically aggressive components are included in the compositions (this applies to water at least). CLF combustion products also have more profound corrosion impact on heat exchange surfaces and smoke removal lines [13,14]. Water-fuel suspensions are characterized by low stability, which complicates their storage, transportation, and their very combustion. In order to prevent stratification of composite fuels by their components and to support rheological properties suitable for the power production industry, specialized surfactants (i.e., stabilizers) must be introduced into compositions $[7,10,15]$.

\subsection{CLF Atomization in the Combustion Chambers of Power Plants}

CLF are normally injected into the combustion chambers of power plants using injectors similar to those used for atomizing conventional liquid fuels. However, due to the rheological, thermophysical, and chemical characteristics of fuel suspensions, the use of standard atomization systems poses certain difficulties $[6,16,17]$. Efficient injection into the combustion chamber while minimizing clogging phenomena is one of the most important problems that emerge when using composite liquid fuels [18]. Optimal fuel atomization parameters facilitate its quick heating and the vaporization of liquid fuel components as well as the escape of volatile components outside the hard ones. This minimizes the phenomena of underburning and allows for supporting the required efficiency of the energy production facility. The minimum droplet size of the polydisperse flux when a CLF is injected into the combustion chamber is limited by the fineness of the solid phase of the CLF (if any). However, when the fuel is fed into the combustion chamber, the maximum possible atomization of droplets is impractical even for compositions that do not contain solid particles. This is because, when droplets are too small, they may deviate from the given trajectory inside the heat exchange chamber. The CLF atomization process is also associated with the problem of rapid clogging of injectors and the corrosion-related phenomena. Therefore, the development of an optimal fuel injection model is the most important task in the design and adaptation of power plants for the use of fuel suspensions.

Pneumatic injectors with separate feeding of fuel suspension and atomizing gas are currently in demand [19-21]. Designs of these injectors may vary. Yet, the common trend is the need to use high pressure gas, which increases the velocity of the polydisperse flux at the injector outlet [19].

Mixing fuel and gas directly in the injector body results in a more even distribution of droplets in the polydisperse flux [22]. Injector designs that implement preliminary mixing of the liquid and gaseous phases are diverse: they rely on bubbling $[18,23]$, special flow restrictors [18,24], as well as multistage mixing [22]. This inevitably complicates the geometry of the atomizing system, while leading to more intensive pollution of its constituents.

A promising direction for improving systems for fuel suspension supply into combustion chambers is the controlled use of the so-called secondary atomization of droplets. This approach allows for reducing the overhead of primary atomization while also avoiding undesirable changes in the trajectory of droplets. These changes may be caused by the effects of the reversal or entrainment by combustion products and adhesion chamber walls [25]. There are several secondary atomization mechanisms. Aerodynamic atomization means droplet atomization caused by their mutual collisions in the flux [26,27] and 
also by collisions with other objects (chamber walls, special structural elements) [28,29]. The thermal atomization mechanism of droplet disintegration is based on the difference between the thermophysical properties of droplet components. This type of atomization can manifest itself when heating inhomogeneous droplets by puffing [30-32] or microexplosion [33-37]. Additionally, there are known technologies for the artificial carbonation of liquid fuels in order to use gas bubbles (for example, $\mathrm{CO}_{2}$ ) as micro-explosion centers [38]. However, in order to adequately describe all the features and regularities of secondary droplet fragmentation (pneumatic, aerodynamic, thermal), it is necessary to carry out large-scale experimental studies. That is why droplet disintegration mechanisms in combustion chambers of power plants are used more often as an additional (even a sideline) method of atomization.

The purpose of this work is to analyze modern solutions for organizing primary and secondary atomization of prospective composite liquid fuels in the combustion chambers of power plants.

\section{Prospective Components of Composite Liquid Fuels}

Since the list of possible CLF components is very extensive and the ratio of their proportions varies, it is extremely difficult to single out an atomization method to suit them all. That is why the investigation of the characteristics of polydisperse CLF fluxes is usually carried out for groups of suspensions that are similar in their compositions and properties. Most often, fuel suspensions similar in composition are united by their scopes of application: coal-water (CW) and organic-coal-water suspensions (OCW) are mainly used in the power production industry. In the transportation sector, compositions based on conventional fuels in combination with various additives are used. Biofuels can be used in different CLF variations as energy and motor fuels.

\subsection{Coal-Water and Organic-Coal-Water Suspensions}

Composite liquid fuels generically include several components to form a homogeneous mixture of combustible and non-combustible components, solid and liquid. The most popular solid combustible components are coals $[11-13,39,40]$ and their derivatives (sludge, filter cake, middlings, semi-coke) [6,9,41]. Peats, solid carbon-containing industrial waste (for example, tire pyrolysis residues) [7], and organic components (sawdust, nutshells and husks, dried algae) $[16,17,42-44]$ can also be successfully utilized in the energy sector as part of CLFs. The most common liquid combustible components include: waste and base oils derived from petroleum (motor, turbine, compressor oils, etc.) [23,33], alcohols [39,45], liquid pyrolysis products, oil sludge and heavy oil $[6,10]$, vegetable oils (including cooking oils), and biodiesel $[16,17,42]$.

Water is a non-combustible binder in fuel suspensions, where the mass fraction of water can be up to $50 \%[11-13,39,40]$. However, suspensions of the listed components are characterized by composition instability due to certain stratification. Therefore, to prevent delamination into components, it is necessary to introduce stabilizing components into the composition. The content of those normally does not exceed 5\% [27,35]. The list of stabilizers being used is very extensive, and the principal requirements include nontoxicity of the initial substance and its combustion products as well as low cost. Apart from increasing the stability of the fuel slurry, stabilizers can also reduce the viscosity of the slurry, which facilitates fuel transport through pipelines and improves atomization performance.

In [9], results of experimental research and numerical analysis of changes in the rheological properties of fuel suspensions based on water, semi-coke powder, and coal sludge with the addition of a dispersant (sodium lignosulfonate) are presented. A decrease in the viscosity of the fuel suspension was shown, and the changes in the electrochemical bonds between the molecules of the mixture were estimated. This change in properties has a positive effect on the applicability of the investigated fuel suspensions in the power production industry. The effect of some other dispersants (sodium humate, sodium dodecyl sulfonate) on the characteristics of a water-fuel suspension of semi-coke powder was 
researched in [9]. The properties of CWs with surfactants were researched both experimentally and using numerical methods, and a satisfactory convergence of the results was shown. The rheological properties of a composite liquid fuel based on tire pyrolysis wastes were researched in [7].

The effect of three different dispersants on the properties of the suspension has been evaluated.

In [40], the rheological and energy characteristics of ultrafine-grained coal-water suspension are investigated.

The research results in [40] substantiate the assumption that as the characteristic sizes of coal particles in the composition are decreased, the ignition temperature and activation energy of fuel suspensions decrease as well.

The data on the thermophysical, heat-engineering, and kinetic characteristics of composite liquid fuels provide important information for the design and adaptation of respective equipment. These data are also useful in the development of tools for mathematical modeling of the processes of motion, atomization, and combustion of composite liquid fuels. That is why the properties of CLF components and their typical mixtures are researched very actively $[2,9,15]$.

\subsection{Anhydrous Composite Liquid Fuels}

Anhydrous fuels based on conventional flammable liquids or mixtures thereof (kerosene, alcohol, gasoline, etc.) $[42,45,46]$ are used mainly as prospective motor fuels [47-49]. Additionally, it is necessary to use surfactants to maintain the stability of such mixtures, especially when solid particles are present.

Such fuel compositions are characterized by high calorific capacities. However, the properties of the mixture change when different components are combined. So, for the adequate design and adaptation of engines to these composite liquid fuels, it is necessary to conduct appropriate research. In [47], changes in the energy parameters of a ramjet engine when burning traditional aviation fuel and when burning a composition with added aluminum nanoparticles are investigated. It is shown that the presence of an admixture of high-energy particles increases the efficiency of fuel combustion and the engine impulse. These results confirm the promising prospective of such fuel compositions. In [42], the results of a study of the characteristics of atomization, ignition, and combustion of a mixture of biofuel from waste cooking oil and amyl alcohol (n-pentanol) are presented. The presence of alcohol improves the ignition characteristics of biodiesel and minimizes the deposition of soot. The data obtained from the research findings in [42] allow for the assertion of the possibility of using such a fuel composition in automobile engines. Nevertheless, the efficiency of combustion of any liquid fuel and, specifically, fuel compositions significantly depends on the parameters of its atomization. Therefore, the development and research of prospective methods of implementing the injection of composite liquid fuels into combustion chambers is an important aspect of improvement of the performance characteristics related to energy production and environment conservation.

\section{Primary Atomization of Composite Liquid Fuels}

The injection of liquid fuel into the combustion chamber has a significant impact on the efficiency of the entire power plant. The completeness of combustion, temperature distribution throughout the volume of the heat exchange chamber, the stability of the flame torch, and other important aspects depend on the parameters of the polydisperse liquid flux. Therefore, it is vital to know optimal atomization parameters in order to maximize fuel efficiency and minimize the environmental impact. Despite the fact that conventional liquid fuels have been used in heat engines and power plants for over 150 years, possible ways to increase their efficiency by optimizing atomization parameters are still being researched [50,51].

In the case of using composite liquid fuels, especially those with solid components in the composition, the search for optimal atomization parameters is complicated not 
only by the rheological and thermophysical characteristics of the mixtures, but also by the higher intensity of erosion phenomena and the contamination of injector device elements. However, most composite liquid fuel atomizers are made of steel, similar to conventional fuel atomizers. Meanwhile, the applicability studies of ceramics for the manufacturing of CLF injectors have yielded results that are known to the public. The article [20] presents a comparative analysis of the wear indicators of injector devices made of different materials (several types of ceramics, carbide, steel) when a coal-water suspension is injected into the combustion chamber. Ceramic injectors have demonstrated the longest service life, while stainless and carbon steel injectors have shown the shortest one. At the same time, the service life of ceramic injectors is 30 times longer than that of steel [20]. However, ceramics have low resistance to cyclic thermal deformation, and this is a disadvantage for the fabrication of CLF atomizers. Due to fragility, microcracks form on the surface of the injectors, which then become the centers of material destruction during operation [18].

\subsection{Injectors with Internal Mixing}

Mixing of the fuel with the atomizing agent is carried out inside the atomizer. Here, a mixture of gas and a finely dispersed flux of suspension flows out from the injector. There are many design options for such injectors. A typical operation mechanism is illustrated by the structures presented in Figure 1: the fuel and atomizing agent (normally air) are pumped into a mixing chamber, out of which a fine gas-fuel mixture flows. Examples of the respective mixing method are shown in Figure 1 (according to $[18,20,24]$ ).

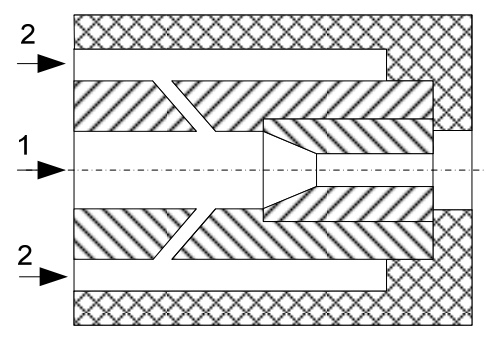

(a)

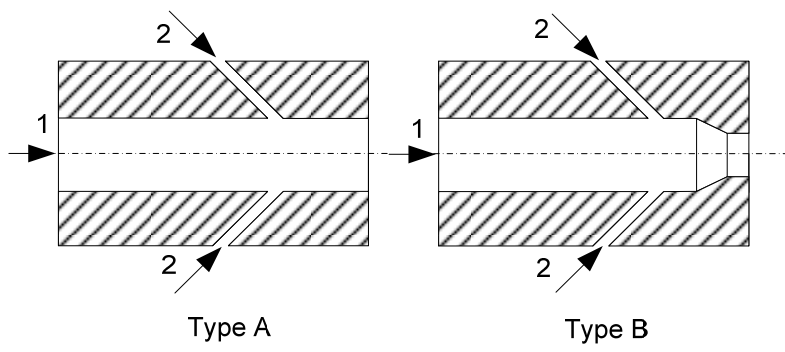

(b)

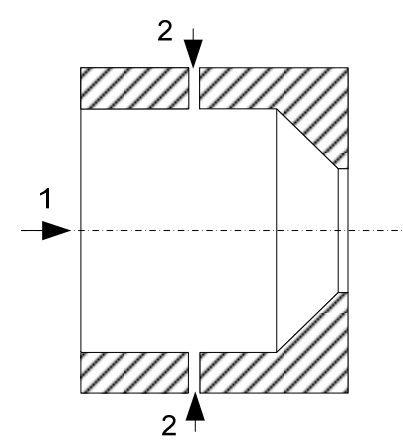

(c)

Figure 1. Designs of typical direct flow injectors with internal mixing (a-c): 1—supply of fuel suspension; 2-supply of atomizing gas.

The characteristics of the coal-water paste (CWP) atomization by direct-flow injectors of two design options were researched in [18]. Peculiarities of CWP lie in the manifestation of non-Newtonian fluid properties. In the experiments, a direct injector and an injector with a restriction device were used (Figure 1b). The atomizing agent (air) was admixed into the fuel through holes located around the circumference of the mixing chamber at an angle of $45^{\circ}$. The mass fuel flow rate was $500 \mathrm{~kg} / \mathrm{h}$, and the injector outlet diameters were 20,32 , and $40 \mathrm{~mm}$. Images of the polydisperse fuel flux were captured using Particle Image Velocimetry (PIV). An analysis of the research findings in [18] has shown that the angle of the CWP atomization varied in the range of $30-35^{\circ}$. In the center of the atomization plume, large droplets were observed. Meanwhile, smaller ones were distributed along the edges and levitated. In this case, as large droplets traveled away from the injector, they 
underwent several stages of transformation: waves, films, and bundles. Then, they broke into smaller droplets under the action of the gas flux and finally formed a finely dispersed multiphase flux. The following conclusions were formulated. Both types of experimental injectors can be used for CWP atomization. However, the injector without tapering showed the best characteristics in terms of the abrasive wear of bearings. The main factor affecting the characteristics of the polydisperse flux of CWPs is the relation between the masses of the fuel and the atomizing agent (i.e., air).

The injectors of three designs were used in [24], including an injector with internal mixing (Figure 1c). Experiments with the atomization of several types of coal-water suspensions have been carried out. The internal mixing atomizer was an air-blown injector with an outlet $5 \mathrm{~mm}$ in diameter. The parameters of the polydisperse flux in the atomization chamber were taken using a Malvern 2600 particle analyzer and a laser-based method of flow diagnostics. The injector performance analysis was based on the calculation of the Sauter droplet diameter and the fuel flow rate. According to the experimental results, the injector with internal mixing has demonstrated the formation of a water-coal suspension flux that was finer in dispersion as compared to other types of injectors. The performance of such an injector also turned out to be the highest. However, in the presence of large particles of the solid component of the fuel composition, there is a high risk of clogging of the internal mixing injector. This risk is due to the energy of the blast air being not sufficient to disintegrate such clogs [24].

The possibilities of using direct mixing injectors not only for the injection of composite fuels into the combustion chamber, but also for the formation of a water-fuel suspension directly in the atomizer cavity are presented in the research [52]. The purpose of using this design is to create an emulsified composite fuel without the addition of surfactants. Since water-fuel emulsions without surfactants in the composition are extremely unstable, they must be formed immediately before the combustion. A schematic diagram of an emulsifying injector with internal mixing is shown in Figure 2 (according to [52]).

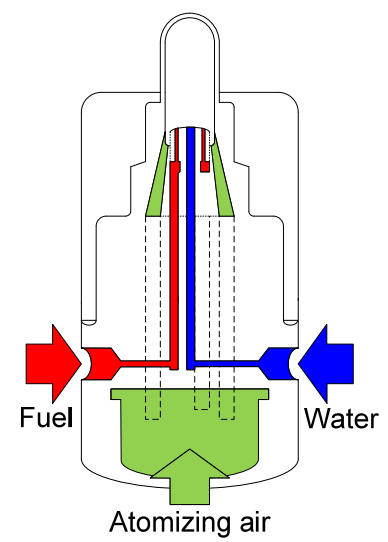

Figure 2. Sectional diagram of the emulsifying injector.

The injector presented in [52] successfully emulsified soybean oil with water at a $50 / 50 \%$ mass fraction of the components. The emulsion was formed by a strong vortex motion of the atomizing gas and the re-mixing in a thin film on the inner walls of the chamber. At the injector outlet, a water-in-oil emulsion was formed. Additionally, despite the fact that the use of such an injector was accompanied by some deterioration in the sputtering parameters (the average droplet diameter according to Sauter was $100 \mu \mathrm{m}$ ), great possibilities for using such a design is substantiated in [52]. The analysis of the combustion of the emulsion formed by the injector developed has made it possible to draw conclusions about the stability of the flame, the high efficiency of fuel combustion, and a reduction in harmful atmospheric emissions.

As general conclusions about the use of direct mixing injectors for the primary atomization of composite liquid fuels, the following can be highlighted: (i) the ratio of the mass 
of the fuel and the atomizing agent must be selected individually for fuel compositions with different characteristics; (ii) empirical data are needed to adjust this ratio adequately; (iii) due to a small number of channels for supplying the atomizing agent, internally mixed injectors are sensitive to the presence of coarse fuel inclusions; and (iv) the phenomenon of the formation of agglomerates from coal particles must be controlled and prevented, especially when preparing fuel compositions in industrial volumes.

\subsection{Injectors with Multi-Stage Mixing}

Injector designs with additional stages for mixing the fuel and the propellant typically have a large number of gas inlets. It is also possible to have special swirlers. The operation mechanism of such injectors is similar to that of uniflow atomizers. Yet, they feature better mixing due to a more sophisticated design and swirling of liquid and gas flows. Examples of typical multistage mixing injectors are shown in Figure 3 (according to [22,24,53].

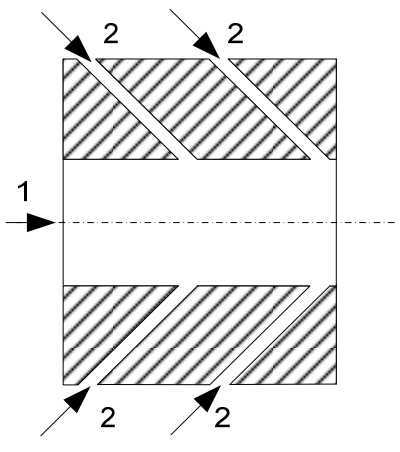

(a)

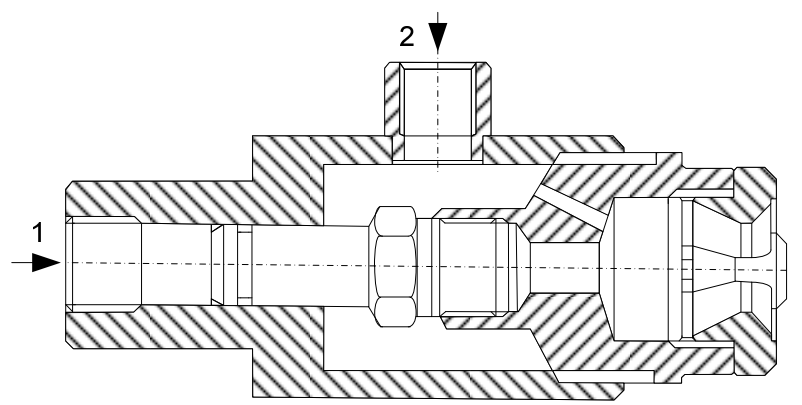

(b)

Figure 3. Typical multi-stage mixing injector schemes (a,b): 1—supply of fuel suspension; 2—supply of atomizing gas.

In [24], a design of a multistage low pressure injector is proposed (Figure 3a). The main advantages of such an injector are as follows: low supply pressure of the coal-water slurry, less intense erosion, as well as protection from clogging. The holes located around the perimeter for supplying the atomizing agent (air) make it possible to atomize solid particles if necessary (in contrast to the direct mixing injector). Particles may become larger as a result of adhesion or poor-quality preparation of the suspension. At the same time, the productivity of the multistage injector turned out to be lower, and the average droplet diameter of the polydisperse flux (according to Sauter) was higher as compared to the direct mixing injector [24]. The parameters of the polydisperse flux of the fuel suspension generated by the multistage injector are more sensitive to the ratio of the mass flow rates of the fuel and the air. However, in [24], it was concluded that multistage injector was versatile and more reliable, because it was able to atomize solid components of low-quality coal-water fuels by air jets.

The results of research of the applicability of a multistage injector [22] for injecting a coal-water suspension into the combustion chamber also confirm that, at the injector outlet, polydisperse flux parameters (in particular, average Sauter diameter) are highly sensitive to the ratio of the fuel-air mixture supplied to the mixing chamber. In [22], it is noted that as the mass flow rate of the air increases, the atomization quality improves: the dispersion of the flux decreases and it becomes more uniform throughout the chamber volume. In addition, the injector design proposed in [22] allows for adjusting the spray angle of the composite liquid fuel.

In [53], a comparison of the characteristics of the atomization of two fuel compositions is made. One composition includes a solid (coal), while another one includes a liquid (petroleum coke). The compositions were atomized using an injector (Figure 3b), which has three holes for gas swirling on the main channel from which composite liquid fuel 
was fed. Furthermore, the injector design includes a special plate: when colliding with the plate, the fuel suspension mixes more intensively. The mixture was discharged from the injector through a special annular channel. Nitrogen was used as an atomization agent [53]. The characteristics of the polydisperse flux were investigated using optical laser diagnostic methods. The experimental results have shown that, when using the same injector design, the angle of the coal-water suspension spray cone is less than that of the aqueous suspension with petroleum coke. The structure of the spray plume is such that larger droplets are located at the periphery of the polydisperse flux, while small droplets predominate in the central part of the plume [53].

Summarizing the results of the research of the applicability of multistage injectors for the atomization of composite liquid fuels, several conclusions can be made. Firstly, due to the complicated design, a more uniform formation of the gas-liquid mixture occurs, which has a positive effect on the characteristics of the fuel flow in the combustion chamber. Secondly, as a positive aspect of the use of multistage injectors, one can note their tolerance to the presence of large particles or clogs in low-quality fuels. However, multistage injectors exhibit high sensitivity to the ratio of the flow rates of the fuel and the atomizing gas $[22,24,53]$.

\subsection{Bubble Injectors}

The design of the injectors that utilize the bubbling of gas through the fuel slurry involves a larger number of holes to supply the atomizing agent. The presence of a solid combustible component in fuel suspensions leads to the contamination of the gas inlet openings. Apart from that, a decrease in the pressure drop between the air and the coal-water slurry was observed in [24], and this decrease caused a blockage of the gas inlets. This is probably due to the presence of coal particles. They either cause the instability of the bubble flux or an increase in the thickness of the coal-water suspension film between bubbles. In [24], a conclusion is made about the inexpediency of using bubbling (effervescent) injectors for the atomization of fuel suspensions having solid components.

In [23], the results of experiments with the atomization of a fuel suspension based on oil sludge using a bubble injector are presented. A diagram of the results is shown in Figure 4 (according to [23]). The fuel slurry consisted of petroleum coke, sewage sludge, and some chemical additives. Due to the hydrophobicity of the oil sludge and the properties of the sewage sludge (it is a non-Newtonian fluid), the atomization rate is low. By analyzing the distribution of droplet sizes in the flux, it was possible to determine the characteristic changes in the droplets as they moved away from the injector. Droplet diameter decreased as the axial distance increased. A conclusion was made about the possibility of using this type of atomizers for fuel suspensions based on liquid combustible components. The size of fuel droplets in the polydisperse flux could be significantly reduced by decreasing the injector outlet cross section and increasing the gas pressure.

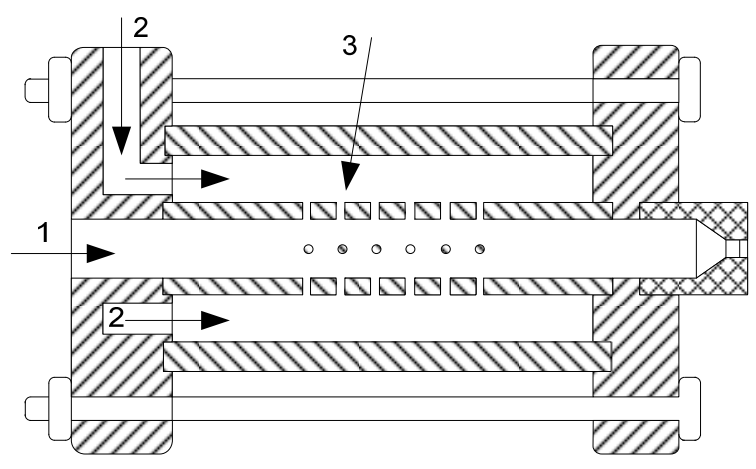

Figure 4. Effervescent injector diagram: 1-supply of fuel suspension; 2-supply of atomizing gas, 3-holes for the gas inlet. 


\subsection{Coaxial Injectors}

This type of atomizer does not envision mixing fuel suspension and gas in the inner space of the injector $[19,21,54]$. A fine gas-liquid flow is formed at the nozzle outlet as result of the interaction of fuel jets with a nebulizer gas, featuring high flow rates. Typical designs of coaxial injectors are shown in Figure 5 (according to $[19,21,54]$ ). The fuel suspension is pumped through the central channel, and the atomization gas travels in the same direction, normally, through several parallel channels. At the injector outlet, the liquid fuel jet is subjected to aerodynamic impact from the gas flows, which results in the jet being converted to a polydisperse flux.
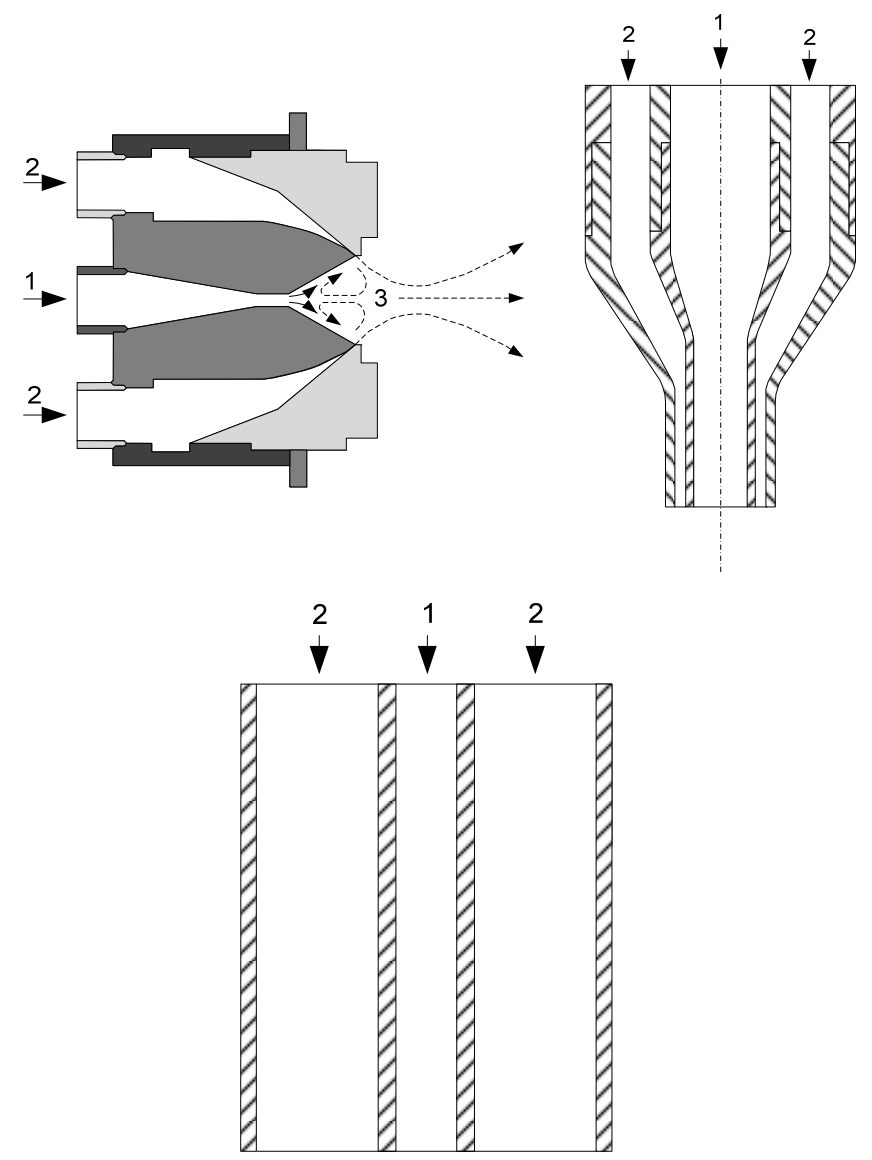

Figure 5. Diagrams of typical coaxial atomizers: 1-supply of fuel suspension; 2-supply of atomizing gas.

In [21], the influence of the rheological properties of a coal-water suspension on the characteristics of atomization is investigated. High-speed video recording was used in the experiments. From the analysis of the recorded video frames, two types of structures in the process of destruction of a fuel jet by the air impact were singled out [21]: shear wave and jet oscillations. Shear wave is typical for the conditions of high fluid velocity and low viscoelasticity. Jet oscillations occurred at high values of viscoelasticity and low velocities [21]. The results obtained illustrate the decisive impact of the rheological properties of composite liquid fuels on the morphology and other parameters of the polydisperse flux.

The results of experimental and theoretical studies of the formation of a finely dispersed flux of composite liquid fuel using a coaxial injector are presented in [19]. The atomizer design presented in [19] allows for the use of the Coandă effect to atomize the fuel suspension. The parameters of the multiphase flux at the injector outlet were diagnosed using the PIV method. The results of the numerical simulation of the sputtering process are presented, and they are in good agreement with the experimental data [19]. The air 
pressure was varied in the range from 1 to 5 bar. Over the entire experimental range of pressures, the structure of the polydisperse flux of the fuel suspension was represented by an annular jet in the symmetry axis area. The flux was forming direct and reverse cumulative axial jets. During the interaction of these jets, a toroidal vortex arose in the diffuser. This vortex facilitated the effective destruction of the liquid substance jet and the formation of a finely dispersed two-phase flux [19]. The results in [19] rather comprehensively characterize the complex aerodynamics of a single-phase flux created by the pneumatic injector being researched.

The research in [54] is also based on an experimental study of the features of the destruction of a jet of a fuel suspension under the influence of an air impact at coaxial injector nozzle outlet. Eight compositions of coal-water suspensions were used in the experiments. The characteristics of the formation of the polydisperse flux were analyzed using highspeed video recording. Numerical simulations complemented the experiments [54]. A good convergence of experimental and theoretical results was achieved. Based on the results of the analysis of the fracture morphology of the fuel suspension jet, the fracture modes have been identified: Rayleigh type rupture, fiber type rupture, and atomization. The Rayleigh type rupture is identified as the main mode of decomposition of high-viscosity compositions of fuel suspensions. At low air velocities, the fiber type rupture prevailed. High air velocities are characterized by intense atomization [54].

The following general conclusions about the features of the formation of a polydisperse flux of fuel suspensions by coaxial injectors can be made. This injector type can be successfully used for the efficient atomization of even highly viscous compositions of composite liquid fuels. However, with an increase in the pressure of the atomization gas, polydisperse flux velocity increases significantly. Thus, it is necessary to empirically determine the necessary and sufficient values of the excess air flow pressure for the efficient conversion of the fuel jet into a finely dispersed flux.

\section{Secondary Atomization of Composite Liquid Fuels}

Interest in the research of the mechanisms of the secondary atomization of fuel droplets directly in the combustion chamber is rather high $[26,28,55,56]$. Droplet dispersion is an important additional means of improving fuel efficiency by ensuring its complete combustion while reducing the atomization overhead. The secondary fragmentation of droplets can occur due to mutual interactions of droplets in the flux [57]. It may also take place upon collision with the channel wall or with an intentionally installed obstacle [29] or due to various internal overheating mechanisms [37,38]. Additionally, the methods of secondary atomization of droplets may provisionally include the impact of gas jets with excess pressure on the polydisperse fuel flux formed by the injector directly in the combustion zone $[27,58,59]$. The morphology of the phenomena of secondary disintegration of droplets is very diverse, and it depends on many factors. Therefore, the controlled use of the atomization process can only be based on a large body of empirical data that form the basis for the development of the respective predictive models $[56,59,60]$.

\subsection{Aerodynamic Mechanism of Secondary Atomization}

This type of secondary decomposition can occur in a droplet flux, regardless of the composition of the liquid and the external factors. The possible outcomes of the droplet collision normally include the following: (i) rebound (elastic repulsion of drops from each other after the contact, while maintaining the integrity of both droplets); (ii) expansion (collision, temporary merger into a single element with further separation into two droplets similar in size to the initial ones); (iii) coagulation (the unification of droplets after the collision); and (iv) fragmentation (the destruction of the parent droplet with the formation of a group of smaller droplets) [26,57]. Typical video frames of each of the listed collision modes are shown in Figure 6 (according to [26]). 

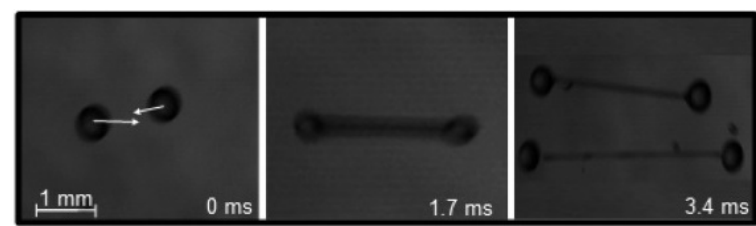

(a)

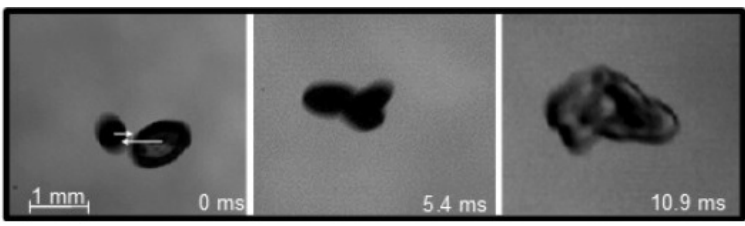

(c)

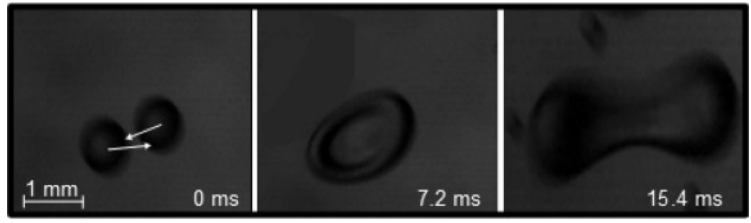

(b)

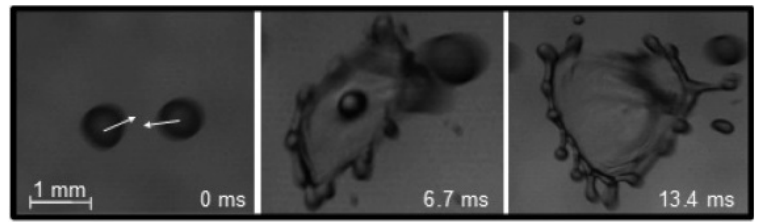

(d)

Figure 6. Typical video frames of the basic modes of binary collisions of fuel suspension droplets: (a) - rebound; (b) - expansion; (c)—coagulation; (d) -fragmentation.

In [26], the conditions for the stable realization of each of the droplet collision modes were determined. The stages of transformation of coal-water suspension droplets were investigated with the help of high-speed video recording. The composition of the composite fuel, the fineness of the grinding of the solid fuel component, the initial velocities of the droplets and their sizes, and the initial temperature of the fuel suspension were varied. It was shown that the droplet fragmentation mode is possible in the entire range of variations of external and internal factors. The conclusion has been formulated, and it states that it is possible to ensure the conditions of intensive secondary fragmentation of droplets even at small values of the Weber and Reynolds numbers. These numbers characterize the forces of inertia, viscosity, and elasticity affecting the droplet. It was shown in [26] that the process of the onset of the fragmentation mode can be controlled by varying the angle of attack of the droplets. In this case, the characteristic ranges of the conditions whereby the occurrence of secondary fragmentation is the most probable differ for fuel compositions with different compositions. Therefore, the most important task is to compose maps of collision modes for a wide group of composite liquid fuels on the basis of empirical data.

In [57], the research findings obtained on a laboratory coal-water slurry gasifier are presented. The peculiarity of the gasifier design lies in the fact that when the fuel is sprayed in its inner chamber, the conditions for primary and secondary fuel atomization are realized. Primary injection was carried out using a coaxial injector. The secondary fragmentation of droplets occurred directly in the flame combustion zone. The stages and features of fragmentation were recorded using high-speed video recording. In [57], tensile rupture and shear rupture are identified as typical types of the fragmentation of fuel suspension droplets. The regions of the gasifier chamber with different flow rates were investigated and the probabilities of the secondary fragmentation of droplets characteristic for each zone have been revealed. Thus, the probability of the absence of droplet fragmentation even in a region with low flow rates is low (about $7 \%$ ). In this case, the most frequently realized scenario of secondary fragmentation of droplets in the region with low flow rates is tensile rupture. At high flow rates, the percentage ratio of tensile rupture and shear rupture are comparable. A conclusion [57] is formulated, postulating the need of using secondary fragmentation of droplets as a possible path for increasing the efficiency of power plants.

Another type of aerodynamic fragmentation of droplets is their collision with various solid surfaces. In [29], the morphology of biodiesel-water microemulsion droplets fragmentation when dropped on a heated substrate was experimentally investigated. By varying such factors as the mass fraction of the surfactant and the heating temperature, the researchers were able to achieve conditions under which secondary atomization is realized with the formation of the so-called corona of fuel splashes. In this case, the relation between the droplet surface area after fragmentation and the initial droplet surface area 
was $S_{1} / S_{0}=19$. It was concluded that the decisive factors affecting the characteristic sizes of secondary droplets are the temperature of the substrate and the proportion of water in the composition of the composite liquid fuel.

The impact of high-pressure gas jets on droplet fluxes of liquids can also be considered as the second stage of atomization, although this method (in contrast to the two above methods) requires additional energy input $[19,27,58]$. The modes and characteristics of the fragmentation of droplets of eight fuel compositions were experimentally investigated in [58]. The modes of deformation and fracture were singled out. They differ from those observed in the case of single-component drops. Deformation without subsequent destruction (analogous to the so-called parachute) is a composite mode comprising two stages: annular and tensile rupture, and shear rupture of droplets [58]. In addition to the classical criteria characterizing the destruction of liquid droplets (We and Oh), new criteria are proposed. They reflect the boundaries of the occurrence of fragmentation modes of non-Newtonian liquids, since composite liquid fuels often exhibit the properties of such liquids.

The experiments in [27] seek to investigate the effect of surfactants in fuel compositions on the morphology of droplet destruction when exposed to a gas jet. Different types of droplet destruction require different conditions for liquid droplets with surfactants as compared to droplets without additional additives. Differences between these conditions have been revealed. The concentrations of micelles and surfactant monomers on the surface of fuel suspension droplets have been studied in detail. This factor is recognized as a decisive one when it comes to differences in droplet breakdown characteristics. Based on the results of the research carried out, a criterion that would make it possible to calculate the value of the Weber criterion with satisfactory accuracy has been proposed. The Weber criterion characterizes the transition boundary between the modes of disintegration of droplets containing surfactants.

It should be noted that the development and constant contribution of experimental data for a wide group of composite liquid fuels into the database is instrumental for the adequate recording of conditions of secondary fragmentation of fuel droplets caused by aerodynamic force, as well as predicting the characteristics of this process.

\subsection{Thermal Mechanism of Secondary Atomization}

The disintegration of multicomponent droplets under heating conditions is most often based on the difference in the thermophysical properties of the substances that comprise the fuel suspension. For example, coal particles included in the composition of certain types of liquid fuel can intensively absorb the radiation component of the heat flux, thereby creating a zone of boiling and vaporization at the interface with the liquid phase [61]. The presence of liquids with different boiling points in the fuel composition also leads to the destruction of the droplet caused by the formation of vaporization products of the low-boiling component [31,32]. Among the typical modes of thermal disintegration of fuel suspension droplets, one can distinguish the so-called puffing. Puffing is the evaporation of a certain amount of liquid from the inner layers, accompanied by the separation of liquid fragments, but without complete destruction of the droplet. Micro-explosion is a complete disintegration of the droplet with the formation of a finely dispersed cloud of liquid.

In [33], the authors researched the factors that make it possible to achieve complete fragmentation of droplets of coal-water and organo-coal suspensions under different heat supply models: on a heated metal substrate $\left(300-600^{\circ} \mathrm{C}\right)$, in high-temperature air flux $\left(450-550^{\circ} \mathrm{C}\right)$, and in a tubular muffle furnace $\left(500-700{ }^{\circ} \mathrm{C}\right)$. During experimental studies, three modes have been observed: monotonous evaporation of droplets, surface transformation with partial separation of the liquid mass in the form of separate fragments, and complete disintegration of a droplet with the formation of splashes. Typical video frames of the main modes of fuel suspensions droplets evaporation are shown in Figure 7 (according to [33]). 


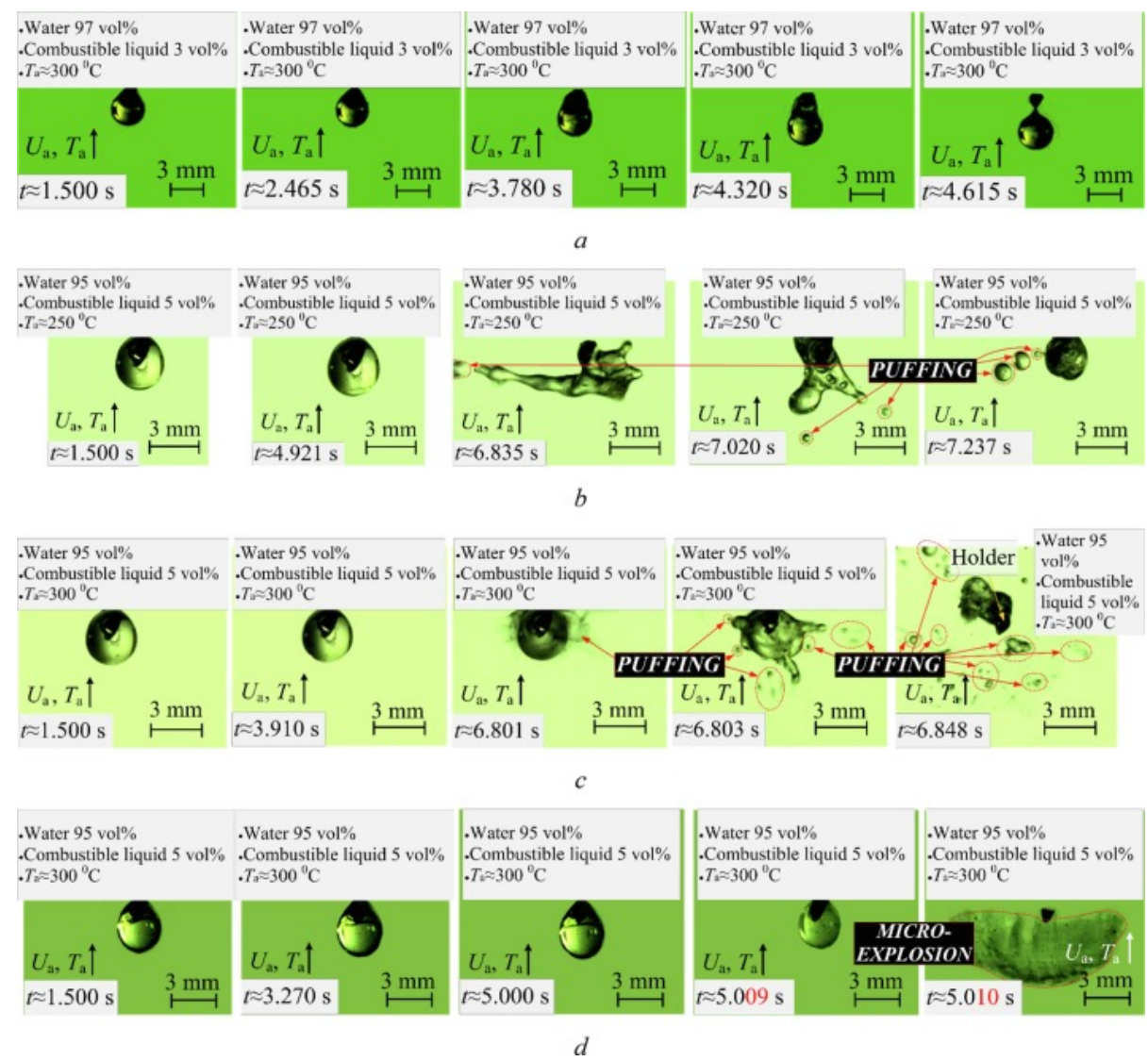

Figure 7. Typical video frames illustrating the principal modes of fuel droplets evaporation: (a) - monotonous evaporation from the free surface; (b) - puffing with the formation of large fragments of liquid; (c) - puffing with the formation of small droplets; and (d) - micro-explosive destruction with the formation of an aerosol cloud.

The research was performed using high-speed video recording and subsequent video frame analysis using specialized software. The following results in [33] are highlighted as the main research findings. The puffing mode is characteristic of droplets of fuels with a fuzzy interface between the media (i.e., fuels without solid particles in the composition). Complete disintegration of droplets occurs due to overheating at the surface of solid fuel inclusions (i.e., it occurs in droplets with a pronounced interface). The fragmentation delay is caused by the evaporation of moisture from the droplet subsurface layers. The ambient temperature is the most important factor for micro-explosion. The temperature range corresponding to low-temperature ignition (up to $900^{\circ} \mathrm{C}$ ) is selected as the most favorable mode in [33]. From the point of view of micro-explosive fragmentation, the most efficient heat supply mode envisions the flow of heated air around the droplet, which corresponds to combustion chamber conditions. The characteristic sizes of droplets and solid fuel particles in their composition have also had impact on the micro-explosion intensity: the smaller the initial droplet and coal particles in its composition, the sooner explosive fragmentation took place. Thus, a recommendation [33] has been formulated. It suggests organizing the combustion of composite fuels in chambers with preliminary heating and fragmentation of droplets in a low-temperature zone with the subsequent entry of the fine-dispersed flux being formed into the combustion chamber.

In [36], a more detailed investigation of the micro-explosive destruction mode, focusing on the formation of the so-called corona is offered. Composite liquid fuel was a mixture of two combustible components with a sharply differing volatility: ethanol and tetradecane. The atomization mode of such a fuel composition is similar to the formation of splashes when a droplet hits a hard surface. The direct impact of the fraction of the volatile component in the droplet on the stability of the formation of a hemisphere of small 
splashes has been determined [36]. That is why the introduction of low-boiling combustible impurities into fuel compositions can be considered an additional means of increasing the probability of micro-explosive destruction.

Another way to intensify the secondary atomization of droplets is the supplementary gasification of the fuel suspension [38]. The water-oil composition was investigated as a model fuel composition. Carbon dioxide microbubbles were introduced into the water-oil emulsion to act as vaporization centers. The gasified and the normal emulsion were heated under identical conditions [38]. For droplets with gas bubbles, smaller values of the ignition delay times were recorded. It was substantiated that the carbonization of emulsified fuel improves the ignition characteristics by enhancing the effect of micro-explosive destruction of droplets.

Thus, based on the experimental results in [31-38], it can be concluded that favorable factors for the stable realization of micro-explosive fragmentation of fuel suspension droplets are as follows: (i) the presence of a clear phase boundary (mainly due to solid inclusions); (ii) a significant difference in the volatility of liquid components; and (iii) the presence of additional nuclei of vaporization (for example, gas microbubbles).

\section{Conclusions}

i. Based on the analysis of modern trends in the development of technologies for the atomization of composite liquid fuels, it can be concluded that the most effective formation of a polydisperse flux of fuel suspensions requires the simultaneous use of primary and secondary atomization modes. It is not possible to develop a universal scheme for the injection of CLFs into the combustion chamber due to a wide variety of fuel components, stabilizing additives, and their ratios in the composition.

ii. Based on the analysis of modern achievements of the global scientific community, it is possible to formulate conclusions regarding primary atomization modes:

a. Injector devices with simple internal mixing allow for the formation of an effective polydisperse flux. However, they are sensitive to the presence of large inclusions of solid particles. When preparing composite liquid fuels with solid additives in industrial volumes, it is difficult to completely exclude the occurrence of such agglomerates.

b. Multistage injectors are more resistant to the presence of large particles. However, their performance and polydisperse flux parameters strongly depend on the ratio between the flow rates of the fuel and the atomizing agent. This requires the use of highly sensitive control systems.

c. It is not advisable to use bubbling injectors for atomizing composite liquid fuels with solid components. However, this type of atomization can be used for suspensions based on liquid components, including those with non-Newtonian properties.

d. Coaxial injectors demonstrate excellent efficiency in the formation of finely dispersed fluxes due to a high degree of turbulence. At the same time, their main disadvantage is high resulting flow rates, including supersonic ones.

iii. When analyzing the methods of secondary atomization of composite liquid fuel droplets, it is substantiated that, for the best use of the aerodynamic mechanism of secondary fragmentation, optimal ranges of motion velocities and mutual trajectories of droplet fluxes should be chosen. In this regard, it is necessary to note that the development of aerodynamic fragmentation mode maps is highly relevant, and these maps can only be obtained from experimental research findings. For the effective implementation of the thermal mechanism of secondary fragmentation, it is necessary to aim for the occurrence of micro-explosive disintegration. The main favorable factors include: the presence of solid inclusions (a clear phase boundary) in the droplets; a significant difference in the volatility of liquid components; and the presence of microcenters where boiling centers nucleation takes place. 
Author Contributions: Conceptualization, R.V., T.V. and O.V.; Writing-original draft, writingreview and editing, O.V. All authors have read and agreed to the published version of the manuscript.

Funding: Research was supported by a grant from the Ministry of Science and Higher Education of Russia, Agreement No 075-15-2020-806 (Contract No 13.1902.21.0014).

Institutional Review Board Statement: Not applicable.

Informed Consent Statement: Not applicable.

Data Availability Statement: Not applicable.

Conflicts of Interest: The authors declare no conflict of interest.

\section{References}

1. Ruhe, C.H.W. Statistical Review. JAMA J. Am. Med. Assoc. 1973, 225, 299-306. [CrossRef]

2. Mohanty, J.K.; Guru, S.R.; Dash, P.; Pradhan, P.K. Fly Ash Management and Condition Monitoring of Ash Pond. Earth Syst. Environ. 2020, 5, 445-457. [CrossRef]

3. Gonzalez-Salazar, M.A.; Kirsten, T.; Prchlik, L. Review of the operational flexibility and emissions of gas- and coal-fired power plants in a future with growing renewables. Renew. Sustain. Energy Rev. 2018, 82, 1497-1513. [CrossRef]

4. Guttikunda, S.K.; Jawahar, P. Atmospheric emissions and pollution from the coal-fired thermal power plants in India. Atmos. Environ. 2014, 92, 449-460. [CrossRef]

5. Wang, G.; Xu, Y.; Ren, H. Intelligent and ecological coal mining as well as clean utilization technology in China: Review and prospects. Int. J. Min. Sci. Technol. 2019, 29, 161-169. [CrossRef]

6. Bogomolov, A.; Valiullin, T.; Vershinina, K.; Shevyrev, S.; Shlegel, N. Igniting Soaring Droplets of Promising Fuel Slurries. Energies 2019, 12, 208. [CrossRef]

7. Zhou, L.; Li, X.; Zhang, R.; Zhou, W.; Jin, J.; Wang, C.; Tian, Y.; Zhang, K. New method for utilizing waste tire pyrolysis residue to prepare slurry fuel: Adsorption and slurry characteristics. Powder Technol. 2021, 386, 236-246. [CrossRef]

8. Ra, H.W.; Mun, T.Y.; Hong, S.J.; Chun, D.H.; Lee, H.T.; Yoon, S.M.; Moon, J.H.; Park, S.J.; Lee, S.H.; Yang, J.H.; et al. Indirect coal liquefaction by integrated entrained flow gasification and Rectisol/Fischer-Tropsch processes for producing automobile diesel substitutes. Energy 2021, 219, 119597. [CrossRef]

9. Meng, Z.; Yang, Z.; Yin, Z.; Li, Y.; Ju, X.; Yao, Y.; Long, J. Interaction between dispersant and coal slime added in semi-coke water slurry: An experimental and DFT study. Appl. Surf. Sci. 2021, 540, 148327. [CrossRef]

10. Cui, L.; An, L.; Jiang, H. A novel process for preparation of an ultra-clean superfine coal-oil slurry. Fuel 2008, 87, 2296-2303. [CrossRef]

11. Shui, H.; Cai, Z.; Xu, C. Recent Advances in Direct Coal Liquefaction. Energies 2010, 3, 155. [CrossRef]

12. Kong, Z.; Dong, X.; Xu, B.; Li, R.; Yin, Q.; Song, C. EROI Analysis for Direct Coal Liquefaction without and with CCS: The Case of the Shenhua DCL Project in China. Energies 2015, 8, 786-807. [CrossRef]

13. Shadrin, E.Y.; Anufriev, I.S.; Butakov, E.B.; Kopyev, E.P.; Alekseenko, S.V.; Maltsev, L.I.; Sharypov, O.V. Coal-water slurry atomization in a new pneumatic nozzle and combustion in a low-power industrial burner. Fuel 2021, 303, 121182. [CrossRef]

14. Singh, A.; Kumar, H.; Kumar, S. Analysis of Tribological Performance of HVOF Sprayed Composite Coatings on Pipeline Material; AIP Publishing: Melville, NY, USA, 2021.

15. Larionov, K.B.; Zenkov, A.V.; Yankovsky, S.A.; Ditc, A.A. Change of coal-water fuel rheological properties by rotary flows modulation. In Proceedings of the 2016 11th International Forum on Strategic Technology (IFOST), Novosibirsk, Russia, 1-3 June 2016; pp. 568-571. [CrossRef]

16. Al-lwayzy, S.H.; Yusaf, T.; Saleh, K.; Yousif, B. The Influence of Emulsified Water Fuel Containing Fresh Water Microalgae on Diesel Engine Performance, Combustion, Vibration and Emission. Energies 2019, 12, 2546. [CrossRef]

17. Long, J.M.; Boyette, M.D. Analysis of Micronized Charcoal for Use in a Liquid Fuel Slurry. Energies 2016, 10, 25. [CrossRef]

18. Lu, P.; Zhang, M. Experimental investigation on atomizing characteristics of coal-water paste for pressurized fluidized bed. Fuel 2004, 83, 2109-2114. [CrossRef]

19. Alekseenko, S.V.; Anufriev, I.S.; Dekterev, A.A.; Kuznetsov, V.A.; Maltsev, L.I.; Minakov, A.V.; Chernetskiy, M.Y.; Shadrin, E.Y.; Sharypov, O.V. Experimental and numerical investigation of aerodynamics of a pneumatic nozzle for suspension fuel. Int. J. Heat Fluid Flow 2019, 77, 288-298. [CrossRef]

20. Deng, J.; Ding, Z.; Zhou, H.; Tan, Y. Performance and wear characteristics of ceramic, cemented carbide, and metal nozzles used in coal-water-slurry boilers. Int. J. Refract. Met. Hard Mater. 2009, 27, 919-926. [CrossRef]

21. Zhao, H.; Hou, Y.B.; Liu, H.F.; Tian, X.S.; Xu, J.L.; Li, W.F.; Liu, Y.; Wu, F.Y.; Zhang, J.; Lin, K.F. Influence of rheological properties on air-blast atomization of coal water slurry. J. Nonnewton. Fluid Mech. 2014, 211, 1-15. [CrossRef]

22. Yu, H.; Zhang, C.; Liu, J.; Cen, K. Experimental Study of the Atomizing Performance of a New Type of Nozzle for Coal Water Slurry. Energy Fuels 2008, 22, 1170-1173. [CrossRef]

23. Ma, X.; Duan, Y.; Liu, M. Atomization of petroleum-coke sludge slurry using effervescent atomizer. Exp. Therm. Fluid Sci. 2013, 46, 131-138. [CrossRef] 
24. Yuan, K.; Chen, L.; Wu, C. Study on characteristics of different types of nozzles for coal-water slurry atomization. J. Therm. Sci. 2001, 10, 331-335. [CrossRef]

25. Volkov, R.S.; Kuznetsov, G.V.; Strizhak, P.A. Analysis of the Characteristics of the Retardation and Entrainment of Droplets in a Polydisperse Water Flow by High-Temperature Gases Under Conditions of Intense Phase Transformations. J. Eng. Phys. Thermophys 2015, 88, 937-947. [CrossRef]

26. Solomatin, Y.; Shlegel, N.E.; Strizhak, P.A. Atomization of promising multicomponent fuel droplets by their collisions. Fuel 2019, 255, 115751. [CrossRef]

27. Zhao, H.; Wu, Z.W.; Li, W.F.; Xu, J.L.; Liu, H.F. Transition Weber number between surfactant-laden drop bag breakup and shear breakup of secondary atomization. Fuel 2018, 221, 138-143. [CrossRef]

28. Breitenbach, J.; Kissing, J.; Roisman, I.V.; Tropea, C. Characterization of secondary droplets during thermal atomization regime. Exp. Therm. Fluid Sci. 2018, 98, 516-522. [CrossRef]

29. Ashikhmin, A.E.; Khomutov, N.A.; Piskunov, M.V.; Yanovsky, V.A. Secondary Atomization of a Biodiesel Micro-Emulsion Fuel Droplet Colliding with a Heated Wall. Appl. Sci. 2020, 10, 685. [CrossRef]

30. Ismael, M.A.; Heikal, M.R.; Aziz, A.R.A.; Crua, C.; El-Adawy, M.; Nissar, Z.; Baharom, M.B.; Zainal A., E.Z.; Firmansyah. Investigation of Puffing and Micro-Explosion of Water-in-Diesel Emulsion Spray Using Shadow Imaging. Energies 2018, 11, 2281. [CrossRef]

31. Watanabe, H.; Shoji, Y.; Yamagaki, T.; Hayashi, J.; Akamatsu, F.; Okazaki, K. Observation of droplet behavior of emulsified fuel in secondary atomization in flame. J. Therm. Sci. Technol. 2014, 9, JTST0009-JTST0009. [CrossRef]

32. Watanabe, H.; Okazaki, K. Visualization of secondary atomization in emulsified-fuel spray flow by shadow imaging. Proc. Combust. Inst. 2013, 34, 1651-1658. [CrossRef]

33. Antonov, D.V.; Kuznetsov, G.V.; Strizhak, P.A. Fragmentation of heated droplets of coal-water slurries containing petrochemicals. Appl. Therm. Eng. 2021, 195, 117190. [CrossRef]

34. Mukhtar, M.N.A.; Hagos, F.Y.; Noor, M.M.; Mamat, R.; Abdullah, A.A.; Abd Aziz, A.R. Tri-fuel emulsion with secondary atomization attributes for greener diesel engine-A critical review. Renew. Sustain. Energy Rev. 2019, 111, 490-506. [CrossRef]

35. Suzuki, Y.; Harada, T.; Watanabe, H.; Shoji, M.; Matsushita, Y.; Aoki, H.; Miura, T. Visualization of aggregation process of dispersed water droplets and the effect of aggregation on secondary atomization of emulsified fuel droplets. Proc. Combust. Inst. 2011, 33, 2063-2070. [CrossRef]

36. Rao, D.C.K.; Karmakar, S. Crown formation and atomization in burning multi-component fuel droplets. Exp. Therm. Fluid Sci. 2018, 98, 303-308. [CrossRef]

37. Faik, A.M.D.; Zhang, Y. Liquid-phase dynamics during the two-droplet combustion of diesel-based fuel mixtures. Exp. Therm. Fluid Sci. 2020, 115, 110084. [CrossRef]

38. Watanabe, H.; Shoji, Y.; Yamagaki, T.; Hayashi, J.; Akamatsu, F.; Okazaki, K. Secondary atomization and spray flame characteristics of carbonated W/O emulsified fuel. Fuel 2016, 182, 259-265. [CrossRef]

39. Gvozdyakov, D.; Zenkov, A. Improvement of atomization characteristics of coal-water slurries. Energy 2021, 230, 120900. [CrossRef]

40. Cheng, J.; Zhou, J.; Li, Y.; Liu, J.; Cen, K. Effects of pore fractal structures of ultrafine coal water slurries on rheological behaviors and combustion dynamics. Fuel 2008, 87, 2620-2627. [CrossRef]

41. Egorov, R.I.; Zaitsev, A.S.; Salgansky, E.A. Activation of the Fuels with Low Reactivity Using the High-Power Laser Pulses. Energies 2018, 11, 3167. [CrossRef]

42. Ma, Y.; Huang, R.; Huang, S.; Zhang, Y.; Xu, S.; Wang, Z. Experimental investigation on the effect of n-pentanol blending on spray, ignition and combustion characteristics of waste cooking oil biodiesel. Energy Convers. Manag. 2017, 148, 440-455. [CrossRef]

43. Jiang, L.; Liang, J.; Yuan, X.; Li, H.; Li, C.; Xiao, Z.; Huang, H.; Wang, H.; Zeng, G. Co-pelletization of sewage sludge and biomass: The density and hardness of pellet. Bioresour. Technol. 2014, 166, 435-443. [CrossRef] [PubMed]

44. Bi, H.; Wang, C.; Lin, Q.; Jiang, X.; Jiang, C.; Bao, L. Combustion behavior, kinetics, gas emission characteristics and artificial neural network modeling of coal gangue and biomass via TG-FTIR. Energy 2020, 213, 118790. [CrossRef]

45. Yu, Y. Experimental study on effects of ethanol-diesel fuel blended on spray characteristics under ultra-high injection pressure up to $350 \mathrm{MPa}$. Energy 2019, 186, 115768. [CrossRef]

46. Kim, H.J.; Suh, H.K.; Park, S.H.; Lee, C.S. An Experimental and Numerical Investigation of Atomization Characteristics of Biodiesel, Dimethyl Ether, and Biodiesel-Ethanol Blended Fuel. Energy Fuels 2008, 22, 2091-2098. [CrossRef]

47. Sun, D.; Cai, W.; Li, C.; Lu, J. Experimental study on atomization characteristics of high-energy-density fuels using a fuel slinger. Energy 2021, 234, 121222. [CrossRef]

48. Jin, Y.; Dou, S.; Yang, Q.; Xu, X.; Fu, Q.; Pan, L. Performance characteristics of a scramjet engine using JP-10 fuel containing aluminum nanoparticles. Acta Astronaut. 2021, 185, 70-77. [CrossRef]

49. Li, S.; Zhuo, Z.; He, L.; Huang, X. Atomization characteristics of nano-Al/ethanol nanofluid fuel in electrostatic field. Fuel 2019, 236, 811-819. [CrossRef]

50. Klein-Douwel, R.J.H.; Frijters, P.J.M.; Somers, L.M.T.; de Boer, W.A.; Baert, R.S.G. Macroscopic diesel fuel spray shadowgraphy using high speed digital imaging in a high pressure cell. Fuel 2007, 86, 1994-2007. [CrossRef]

51. Sparacino, S.; Berni, F.; D’Adamo, A.; Krastev, V.K.; Cavicchi, A.; Postrioti, L. Impact of the Primary Break-Up Strategy on the Morphology of GDI Sprays in 3D-CFD Simulations of Multi-Hole Injectors. Energies 2019, 12, 2890. [CrossRef] 
52. Mohd Arshad, A.S.; Nada, Y.; Kidoguchi, Y.; Asao, D.; Yoshimura, S. Rapid emulsification of a fuel-water rapid internal mixing injector for emulsion fuel combustion. Energy 2019, 167, 35-46. [CrossRef]

53. Daviault, S.G.; Ramadan, O.B.; Matida, E.A.; Hughes, P.M.; Hughes, R. Atomization performance of petroleum coke and coal water slurries from a twin fluid atomizer. Fuel 2012, 98, 183-193. [CrossRef]

54. Zhao, H.; Liu, H.F.; Xu, J.L.; Li, W.F.; Cheng, W. Breakup and atomization of a round coal water slurry jet by an annular air jet. Chem. Eng. Sci. 2012, 78, 63-74. [CrossRef]

55. Rao, D.C.K.; Karmakar, S.; Basu, S. Atomization characteristics and instabilities in the combustion of multi-component fuel droplets with high volatility differential. Sci. Rep. 2017, 7, 8925. [CrossRef] [PubMed]

56. Tavangar, S.; Hashemabadi, S.H.; Saberimoghadam, A. CFD simulation for secondary breakup of coal-water slurry drops using OpenFOAM. Fuel Process. Technol. 2015, 132, 153-163. [CrossRef]

57. Xue, Z.; Gong, Y.; Guo, Q.; Wang, F.; Yu, G. Visualization study on breakup modes of coal water slurry in an impinging entrained-flow gasifier. Fuel 2019, 244, 40-47. [CrossRef]

58. Zhao, H.; Liu, H.F.; Xu, J.L.; Li, W.F. Secondary breakup of coal water slurry drops. Phys. Fluids 2011, 23, 113101. [CrossRef]

59. Minakov, A.V.; Shebeleva, A.A.; Strizhak, P.A.; Chernetskiy, M.Y.; Volkov, R.S. Study of the Weber number impact on secondary breakup of droplets of coal water slurries containing petrochemicals. Fuel 2019, 254, 115606. [CrossRef]

60. Zuzio, D.; Estivalezes, J.L.; Villedieu, P.; Blanchard, G. Numerical simulation of primary and secondary atomization. Comptes Rendus Mécanique 2013, 341, 15-25. [CrossRef]

61. Antonov, D.V.; Nyashina, G.S.; Strizhak, P.A.; Romanov, D.S. Micro-explosive droplet fragmentation of environmentally promising coal-water slurries containing petrochemicals. Fuel 2021, 283, 118949. [CrossRef] 